\title{
Endogenous Pain Modulation
}

\author{
Chapter 13
}

\section{Descending Inhibitory Systems}

\author{
ANTTI PERTOVAARA*1 AND ARMANDO ALMEIDA ${ }^{2}$ \\ ${ }^{1}$ Department of Physiology, Institute of Biomedicine, University of Helsinki, Helsinki, Finland \\ ${ }^{2}$ Life and Health Sciences Research Institute, School of Health Sciences, University of Minho, Braga, Portugal
}

\subsection{General Characteristics of Descending Pain Inhibitory Controls}

It is well established that the brainstem has a significant role in regulating pain-related signals at the spinal cord level (for comprehensive reviews see Willis and Coggeshall, 1991; Sandkühler, 1996; Fields and Basbaum, 1999; Millan, 2002). It has been commonly considered that brainstem-spinal pathways predominantly inhibit pain. However, there is accumulating evidence indicating that descending pathways also have pain facilitatory effects (Urban and Gebhart, 1999; Pertovaara, 2000; Lima and Almeida, 2002; Vanegas and Schaible, 2004; see also Chapter 14 in this volume). In this brief review we focus on descending pain inhibitory systems. First, we describe general characteristics of brainstem-spinal pain inhibitory mechanisms. This is followed by a description of some key structures involved in descending pain inhibition.

\section{(a) Development and Modulatory Properties of Descending Inhibitory Controls}

Descending pain inhibitory pathways originate in or relay through a number of brainstem nuclei. Each pathway has a different neurochemistry and different neuroanatomical connections. It should be noted that some of the brainstem nuclei are involved not only in descending but also ascending inhibition of pain-related responses (Morgan et al., 1989). Descending pain inhibitory controls are immature at birth and do not become functionally effective until postnatal day 10 in the rat (Fitzgerald and Koltzenburg, 1986), although all descending projections are already present at birth (Leong et al., 1984). With advanced age the function of descending pain inhibition is impaired and this is associated with a loss of noradrenergic and serotoninergic fibers in the spinal dorsal horn (Iwata et al., 2002). Conditioning noxious stimulation, which presumably activates descending pain modulatory pathways, has induced a weaker pain suppressive effect in females than in males (Staud et al., 2003) suggesting that descending inhibitory controls may have gender-specific differences. In addition to gender, other genetic differences in descending pain inhibition also exist and they may contribute to individual variability in pain sensitivity. For example, it has been demonstrated that the descending projection and the pain inhibitory influence of the noradrenergic locus coeruleus varies with the strain of animals; i.e. locus coeruleus stimulation inhibits pain-related responses only in a strain of animals with coerulo-spinal axonal projections to the spinal dorsal horn (West et al., 1993).

Since early studies on brainstem stimulationinduced analgesia (Reynolds, 1969; Mayer et al., 1971) it has been reported that descending inhibitory controls produce a selective attenuation of pain-related responses. However, in some experimental conditions responses of innocuous as well as nociceptive neurons of the spinal dorsal horn may be attenuated following stimulation of the brainstem nuclei involved in antinociception (e.g. Gray and Dostrovsky, 1983). Although the somatotopic organization of descending inhibitory influence is quite diffuse, a preferential ipsilateral antinociception induced by electrical stimulation of the midbrain periaqueductal gray (PAG) indicates that the descending inhibitory effect may not be equally distributed

*Correspondence to: Dr. A. Pertovaara, Biomedicum Helsinki, Biomedicine/Physiology, Haartmaninkatu 8, POB 63, University of Helsinki, 00014 Helsinki, Finland. E-mail: Antti.Pertovaara@ helsinki.fi Tel.: +358-9-191 25280; Fax.: +358-9-191 25302. 
throughout the body (Levine et al., 1991). Tonic influence of descending controls has been studied by blocking brainstem-spinal pathways. At behavioral level, the net effect caused by a block of descending pathways is predominantly facilitation of reflexes, although the descending influence depends on a number of factors such as submodality of test stimulation (e.g. Kauppila et al., 1998); in particular noxious heat-evoked reflex responses are markedly enhanced distal to a spinal block indicating that heat-evoked reflex responses are under strong tonic inhibition in intact animals. Recordings of putative pain-relay neurons of the spinal dorsal horn indicate that at single neuron level a block of descending pathways commonly results in facilitation of noxious heat-evoked responses (Dickhaus et al., 1985; Pertovaara, 1999), although the effect of a block of descending pathways may vary from excitation to inhibition depending on the response characteristics and laminar location of the spinal dorsal horn neuron (Laird and Cervero, 1990); this is in line with the evidence showing a differential effect of specific brain areas upon superficial versus deep nociceptive neurons (Rees and Roberts, 1993). Following local lesions of certain lateral structures in the brainstem (Hall et al., 1982), such as the caudal ventrolateral medulla (Tavares and Lima, 2002), tonic descending inhibition of spinal nociceptive neurons was reduced, whereas a lesion of medial structures of the brainstem, such as the raphe nuclei and the PAG, had only a minor effect on tonic descending inhibition (Hall et al., 1982). This finding obtained in healthy, control animals suggests that mechanisms underlying tonic and phasic descending inhibition at least partly dissociate; in physiological conditions lateral structures of the brainstem have a major role in tonic descending inhibition of pain.

Depending on the descending pathway, the pain inhibitory effect may be a parallel rightward shift in the stimulus-response function or a decrease in the slope of ascending nociceptive responses (Carstens et al., 1980). Following a rightward shift of the stimulusresponse function, both the threshold and suprathreshold responses of spinal neurons are attenuated, whereas following a selective decrease in the slope (or gain) of the stimulus-response function the inhibition is observed only with suprathreshold responses. This should be taken into account when testing analgesic compounds or manipulations potentially acting through brainstespinal pathways. Namely, studies addressing the involvement of brainstem-spinal pathways and focusing only on the pain threshold may miss inhibition of suprathreshold pain caused by a selective decrease of gain in spinal relay neurons. In addition, brainstemspinal pathways contribute to regulation of spatial (Bouhassira et al., 1995) and temporal (Pertovaara, 1999) summation in spinal nociceptive neurons. This includes tonic descending inhibition of the long-term potentiation of stimulus-evoked synaptic responses, a putative neural correlate for "pain memory" in the spinal dorsal horn (Sandkühler and Liu, 1998).

\section{(b) Spinal Mechanisms Mediating the Descending Pain Inhibitory Action}

A number of mechanisms are involved in mediating the descending inhibitory effect at the spinal dorsal horn level (Fig. 13.1). Descending axon terminals have direct contacts with presumed pain-relay neurons of the spinal dorsal horn (e.g. Westlund et al., 1990), electrical stimulation of the brainstem induced inhibitory postsynaptic potentials in nociceptive neurons of the spinal dorsal horn (Giesler et al., 1981; Light et al., 1986) and spinal application of noradrenaline, a transmitter released from descending axons, hyperpolarized a population of nociceptive spinal neurons (North and Yoshimura, 1984). These findings indicate that neurotransmitters released from descending axons may block the ascending pain signal by producing a hyperpolarization of spinal relay neurons (direct postsynaptic inhibition; Fig. 13.1A).

Descending pathways may also suppress nociceptive signals due to action on central terminals of primary afferent fibers (presynaptic inhibition). Accordingly, central terminals of nociceptive primary afferents have receptors for neurotransmitters released in the spinal cord only by descending axons, such as noradrenaline (Stone et al., 1998). In line with this, postsynaptic responses evoked by dorsal root stimulation in a population of lamina II neurons of the spinal dorsal horn were reduced by noradrenaline, without influence on direct activation of the same neurons by excitatory amino acids (Kawasaki et al., 2003). Due to rareness of axo-axonic synapses between nociceptive primary afferent nerve fibers and central neurons, it has been proposed that volume transmission may play a major role in presynaptic inhibition of nociception in the spinal dorsal horn (Rudomin and Schmidt, 1999); i.e. neurotransmitter released by descending axons diffuses further away to suppress presynaptically the peripheral afferent volley in nociceptive nerve fibers (Fig. 13.1C).

Superficial laminas of the spinal dorsal horn have a population of interneurons containing inhibitory neurotransmitters such as $\gamma$-aminobutyric acid (GABA), glycine and enkephalin (Ruda et al., 1986). Descending pathways excite some of these putative inhibitory interneurons of the spinal dorsal horn (Millar and Williams, 1989) and this provides one more mechanism for descending inhibition of spinal pain-relay neurons (indirect inhibition via excitation of inhibitory interneurons; Fig. 13.1B). 


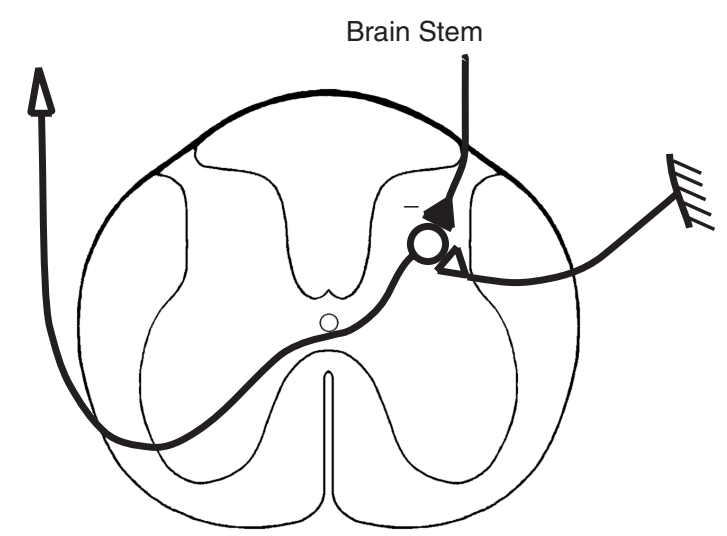

A

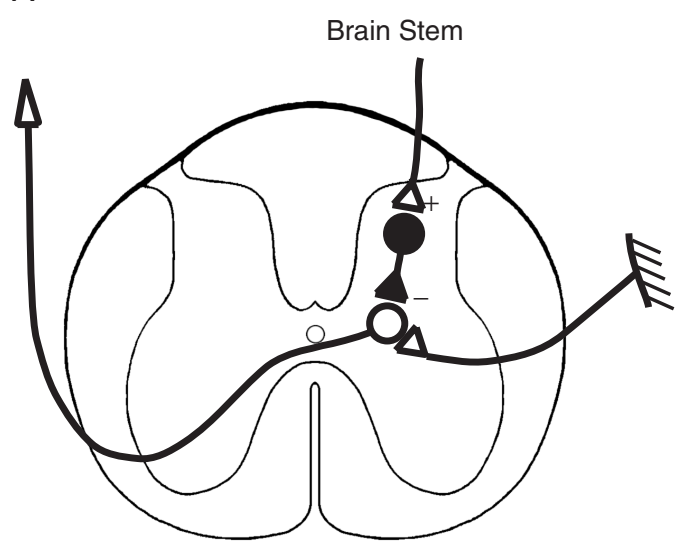

B

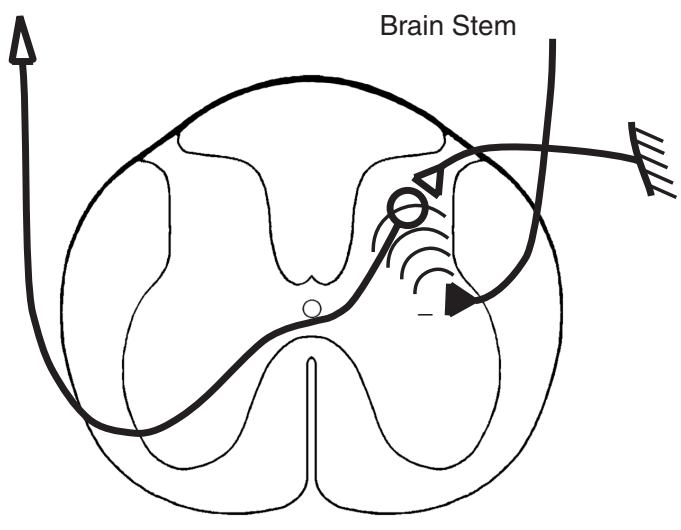

C

Fig. 13.1. Spinal mechanisms mediating the descending pain inhibitory effect. (A) Direct (postsynaptic) inhibition of spinal pain-relay neurons. (B) Indirect inhibition of spinal painrelay neurons through activation of inhibitory interneurons. (C) A hypothetical scheme for volume transmission of an inhibitory neurotransmitter from the descending axons to central terminals of nociceptive primary afferent nerve fibers (presynaptic inhibition of nociceptive afferent barrage to the spinal cord). In each diagram, open symbols represent excitatory synapses and neurons, whereas filled symbols represent inhibitory actions.

\section{(c) Physiological Significance of Descending} Pain Inhibition

Descending pain inhibitory pathways have an important role in the ascending-descending circuitry, providing negative feedback control of nociceptive signals at the spinal cord level (Fields and Basbaum, 1999); i.e. a painful stimulus activates brainstem nuclei involved in descending antinociception and prevents excessive pain by attenuating the successive painful signals. This implies that a full activation of descending inhibition is observed only under painful conditions. The activation of descending inhibitory controls by a painful stimulus may not only serve reduction of excessive pain by negative feedback but it may also help in sharpening up of the contrast between the stimulus site and adjacent areas (Le Bars et al., 1979a,b). Higher nervous system activity controlling behavior provides another physiological way to recruit descending pain modulatory pathways, as shown by the modulation of responses of nociceptive spinal neurons by behavioral context and attention (Dubner, 1985). Similarly, mood and emotions may modulate pain through action on descending pain modulatory pathways (Suzuki et al., 2004). Importantly, analgesia induced by some centrally acting drugs involves activation of descending pain inhibitory pathways.

\section{(d) Descending Pain Inhibition under Pathophysiological Conditions}

Pathophysiological conditions may cause complex changes in descending pain regulatory circuitry. Enhanced tonic descending inhibition has been described in inflamed animals (Schaible et al., 1991; Tsuruoka and Willis, 1996; Mansikka et al., 2004). Also, phasic descending inhibition was stronger following inflammation as indicated by enhanced spinal antinociceptive effect by midbrain stimulation in inflamed animals (Morgan et al., 1991). Inflammation has been associated with increased turnover of noradrenaline (Weil-Fugazza et al., 1986) and increased number of $\alpha_{2}$-adrenoceptors in the spinal cord (Brandt and Livingston, 1990). These changes are likely to contribute to an increase in descending pain inhibition, and they probably explain the enhanced antinociceptive potency of spinally administered $\alpha_{2}$-adrenoceptor agonists in inflamed conditions (Stanfa and Dickenson, 1994; Mansikka et al., 1996). The inflammation-induced increase in ascending nociceptive barrage may contribute to triggering and maintenance of increased inhibitory controls. However, increased efficacy of glutamatergic receptors of the medulla, accompanied by a phenotypic switch of medullary neurons, has also been observed following inflammation (Ren and Dubner, 1996; Miki et al., 2002). 
These findings indicate that plastic changes at the medullary level contribute to maintenance of enhanced descending inhibition following inflammation (Ren and Dubner, 2002). In contrast, phasic descending inhibition of spinal dorsal horn neurons has been reduced following a peripheral nerve injury (Hodge et al., 1983; Pertovaara et al., 1997) but not following development of diabetic neuropathy (Kamei et al., 1992; Pertovaara et al., 2001). On the other hand, peripheral nerve injury may result in compensatory up regulation of descending noradrenergic innervation to the lumbar dorsal horn (Ma and Eisenach, 2003); this upregulation of noradrenergic innervation probably explains the enhanced antinociceptive potency of spinally administered synthetic $\alpha_{2}$-adrenoceptor agonists following nerve injury (Xu et al., 1992) and in some cases it may be enough to mask neuropathic symptoms (Xu et al., 1999). Additionally, nerve injury or inflammation may activate descending facilitation (Urban and Gebhart, 1999; Pertovaara, 2000; Lima and Almeida, 2002; Porreca et al., 2002). Following injury or inflammation, the net effect of descending controls depends on many factors such as submodality of pain, pathophysiological condition (Kauppila et al., 1998), time from the start of the injury (Ren and Dubner, 1996; Danziger et al., 1999), location of the test site in the injured versus uninjured area (Urban and Gebhart, 1999; Vanegas and Schaible, 2004) and the brain area that is experimentally manipulated (Almeida et al., 1999). Increased inhibitory controls potentially help to maintain the capacity to use an inflamed body part for flight or fight in case of emergency, whereas decreased inhibition or increased facilitation of pain might in some cases help the healing process by promoting immobilization and protection of the injured region (McNally, 1999). However, a prolonged decrease of pain inhibition or increase of pain facilitation may not serve any useful purpose, but they just cause unnecessary suffering and may underlie development of chronic pain syndromes.

Motor control and pain regulatory systems share many common neurotransmitters. Disorders of neurotransmitter systems in the motor control circuitries of the basal forebrain are quite common and they are known to be associated with motor dysfunction such as in Parkinson's disease (DeLong, 2000). In analogy, it may be proposed that similar disorders of neurotransmitter systems potentially occur also in pain regulatory circuitries and can underlie some chronic pain conditions by causing hypofunction of descending inhibitory controls. This possibility is supported by a recent series of studies indicating that striatal dopamine D2 receptorbinding potential is associated with the occurrence of chronic orofacial pain as well as baseline pain sensitivity (Hagelberg et al., 2004); i.e. hypofunction of the nigrostriatal dopamine system may cause not only motor disorders but also chronic pain. Further studies are needed to determine potential dysfunctions of other neurotransmitter systems in pain inhibitory pathways and their possible relationship with chronic pain.

\section{(e) Diffuse Noxious Inhibitory Controls}

The application of conditioning noxious stimulation to one area of the body is capable of inhibiting responses of the presumed pain-relay neurons of the spinal dorsal horn evoked by stimulation of other body areas. This implies that painful stimulation inhibits concurrent pain signals evoked from heterotopic stimulation sites allowing focusing of the sensory system on the most dangerous stimulus; this mechanism is called diffuse noxious inhibitory controls (DNIC) (Le Bars et al., 1979a,b). DNIC involves an opioid link and it has also been described in humans (Pertovaara et al., 1982; Willer et al., 1984). Although DNIC involves a descending inhibitory influence, it has been postulated that the net effect of DNIC is facilitation of pain perception evoked by the most threatening noxious stimulus; i.e. the strongest painful stimulus may become more prominent due to activation of DNIC and a consequent suppression of concurrent signals from other body areas. In line with this, the caudal brainstem area implicated in descending inhibition of heterotopic nociceptive signals (i.e. involved in DNIC), the dorsal reticular nucleus of the medulla (Bouhassira et al., 1992), was shown to have a descending pronociceptive action on spinal nociceptive transmission mediated by homotopic neurons (Almeida et al., 1996, 1999; Dugast et al., 2003). Counter-irritation phenomena, including acupuncture, may, at least partly, be based on DNIC (Bing et al., 1990). In experimental models of acute inflammation, the effect of DNIC corresponds with excitatory drives evoked by conditioning and test stimulation; i.e. the DNIC effect is enhanced, when the conditioning noxious stimulation is applied to a hyperalgesic site and the test stimulus to a healthy site, and vice versa (Calvino et al., 1987; Kalmari and Pertovaara, 2004). However, following development of chronic arthritis in experimental animals the magnitude of DNIC was reduced and not associated with the strength of the excitatory drive induced by conditioning or test stimulation (Danziger et al., 1999). Clinical studies indicate that in patients with fibromyalgia a reduction of DNIC potentially contributes to hyperalgesia (Kosek and Hansson, 1997). In neuropathic pain patients the effect of DNIC has varied from a differential influence on on-going versus evoked pain (Witting et al., 2003) to a selective supraspinal inhibition of concurrent pain (Bouhassira et al., 2003). 


\section{(f) Clinical Manipulation of Descending Inhibitory Systems}

Stimulation of descending inhibitory systems has been used for treatment of various pain syndromes (Meyerson, 2001). This treatment method is based on the fact that the amygdala-(PAG)-rostral ventromedial medulla (RVM)-dorsal horn endogenous antinociceptive system is endowed with high concentrations of opioid receptors in every relay station (Mansour et al., 1994; Yaksh, 1997). Chronic deep brain stimulation has been used for the treatment of chronic central pain for decades but, although potentially successful, the electrical stimulation by chronic implanted electrodes of traditional pain-inhibiting centers (e.g. PAG) in humans (Hosobuchi, 1986) had multiple side effects (Tasker, 1982) and therefore it was gradually abandoned. However, there are other areas that can be stimulated with success like the ventrobasal (sensory) thalamus (Vilela Filho, 1994), medial thalamus (Krauss et al., 2002), basal ganglia (Eltahawy et al., 2004), periventricular gray area (Nandi et al., 2003) and posterior hypothalamus (Franzini et al., 2003). A series of clinical studies reported that electrical stimulation of the motor cortex produces variable degrees of pain relief (reviewed by Brown and Barbaro, 2003). Motor cortex stimulation was effective in patients with post-stroke pain (Katayama et al., 2001), phantom limb pain (Sol et al., 2001), neuropathic facial pain (Rainov and Heidecke, 2003) and brachial plexus avulsion-related pain (Saitoh et al., 2001). Experimental animal studies suggest that some forms of behavioral pain therapy may involve modulation of spinal neuronal activity via descending pain-control systems (Dubner, 1985). Moreover, pain treatment by some centrally acting drugs is based on enhancement of descending inhibitory controls.

\subsection{Functional Organization of the Descending Pain Inhibitory Systems}

\section{(a) The Forebrain-PAG-RVM-spinal Pain Inhibitory Circuitry}

\section{The PAG-RVM System: Circuitry in the Midbrain} and Medulla

The PAG matter, located in the mesencephalon around the Sylvius aqueduct was the first brain area shown to exert a powerful pain inhibitory action (Reynolds, 1969) and its pain modulatory role has been exhaustively studied by numerous laboratories (for a review see Fields and Basbaum, 1999; Fig. 13.2). The lack of a strong projection from the PAG to the spinal cord led to the discovery of a relay, the RVM, through which the

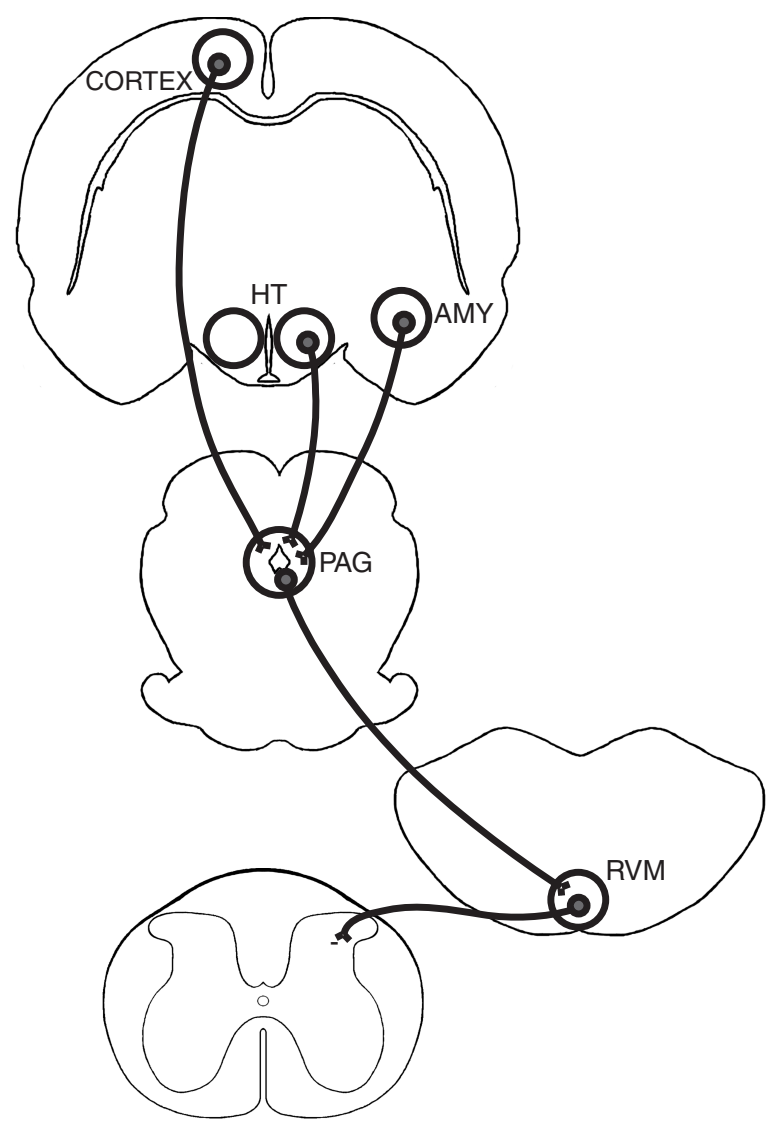

Fig. 13.2. The midbrain periaqueductal gray (PAG)-rostral ventromedial medulla (RVM)-spinal cord pathway. Descending pain inhibitory influence from many areas of the brain is mediated through the PAG-RVM-spinal cord pathway. $\mathrm{HT}=$ hypothalamus; AMY= amygdala.

PAG influences spinal nociception (Behbehani and Fields, 1979; Gebhart et al., 1983). Both the PAG and $\mathrm{RVM}$ receive direct projections from the spinal dorsal horn and, thus, they may control the ascending nociceptive input by a feedback mechanism (Fields and Basbaum, 1999). The RVM includes the nucleus raphe magnus and adjacent reticular formation, including the nucleus gigantocellularis pars $\alpha$ and paragigantocellularis ventralis, all of which project directly to the spinal cord (Newman, 1985). Based on their physiological response properties, spinally projecting RVM neurons can be classified into three types:

1) On cells that give an excitatory response to a noxious stimulus starting just prior to a spinal nocifensive reflex.

2) Off cells that give an inhibitory response to a noxious stimulus starting just prior to a spinal nocifensive reflex.

3) Neutral cells that give variable responses or are unresponsive to noxious stimuli (Fields et al., 1991). 
Both on and off cells are activated by electrical stimulation of the PAG. Importantly, morphine applied systemically or in the PAG suppresses on-cell activity, increases off-cell activity and has little effect on neutralcell activity (Fields and Basbaum, 1999). Additionally, morphine administered into the RVM suppresses directly on- but not off-cell activity (Heinricher et al., 1992); morphine-induced increase of off-cell activity is indirect through a GABAergic mechanism within the RVM (Fields and Basbaum, 1999). These findings suggest that on and off cells of the RVM and supraspinal opioid receptors have an important role not only in antinociception induced by administration of morphine but also in general in descending inhibitory controls relaying through the PAG and RVM. The pain modulatory role of neutral cells of the RVM is less clear. It is known that a subgroup of neutral cells are serotoninergic (Mason, 1997); serotoninergic RVM cells project to the spinal cord (Lakos and Basbaum, 1988) and spinal serotonin receptors contribute to descending antinociceptive influence induced by stimulation of the RVM or PAG (Rivot et al., 1984; Aimone et al., 1987). Although these findings indicate a significant pain modulatory role for a serotoninergic subpopulation of neutral cells, noxious stimulation or morphine produce little or no effect on neutral-cell discharge as expected if their discharge rate was critical for descending inhibitory controls (Heinricher et al., 1992). Serotoninergic neutral cells possibly contribute to spinal antinociceptive action by modulating the effects induced by on and off cells. Interestingly, pain-modulatory effect descending from the RVM is biphasic as indicated by the finding that stimulation of the RVM at sub-antinociceptive intensities enhances spinal nociception (Zhuo and Gebhart, 1990; Gebhart, 2004).

\section{The PAG-RVM System: Circuitry at the Spinal Cord Level}

The dorsolateral funiculus is the main descending pathway mediating antinociceptive effects from the RVM to the spinal dorsal horn (Basbaum et al., 1976). A number of neurochemical and neurophysiological mechanisms contribute to spinal antinociceptive effect induced by stimulation of the PAG or RVM: (i) among the paininhibitory neurotransmitters are monoamines, amino acids and neuropeptides (Jensen and Yaksh, 1984); (ii) among the neurophysiological inhibitory mechanisms at the spinal cord level are postsynaptic inhibition of pain-relay neurons (Giesler et al., 1981), activation of inhibitory interneurons (Millar and Williams, 1989) and presynaptic inhibition of afferent barrage from the primary afferent nociceptive nerve fibers. However, lack of a significant effect by stimulation of the PAG and RVM on excitability of central terminals of primary afferent nociceptive nerve fibers suggests that presynaptic inhibition of afferent barrage to the spinal cord may not have a major role in descending inhibition originating in the PAG-RVM circuitry (Morton et al., 1997; in contrast, Martin et al., 1979). It should also be noted that the activation of the PAG-RVM-spinal cord pathway might recruit other parallel descending pain inhibitory pathways. Namely, the association of the antinociception induced by PAG stimulation with a spinal release of noradrenaline (Cui et al., 1999) and its attenuation by a spinally administered $\alpha_{2}$-adrenoceptor antagonist (Peng et al., 1996) may be explained by recruitment of a spinally projecting noradrenergic cell groups of the brainstem, such as A7 or the locus coeruleus (Sim and Joseph, 1992; Bajic and Proudfit, 1999).

\section{The PAG-RVM system: convergence from}

other pain modulatory areas

A large number of brainstem, diencephalic (thalamic and hypothalamic) and telencephalic (cortical and subcortical) structures suppress pain through descending projections to the spinal dorsal horn, and in most cases their descending pain suppressive effect is relayed through the PAG and the RVM [e.g. the ventrolateral orbital cortex (Dong et al., 1999), prefrontal cortex (Hardy, 1986), amygdala (Helmstetter et al., 1998), parafascicular thalamic nucleus (Sakata et al., 1989) and lateral hypothalamus (Aimone and Gebhart, 1988)]. These findings suggest that the RVM is the final relay station for descending antinociceptive action from most structures of the forebrain (Gebhart, 2004; Fig. 13.2).

Experimental and clinical studies show interactions between pain and emotions (Price, 2000). Amygdala plays an important role in emotional behavior. Nociceptive inputs through the spino-parabrachio-amygdala pathway probably contribute to pain-induced changes in affective behavior (Bernard et al., 1996), and the projections of the amygdala to the PAG-RVM circuitry may be involved in mediating the influence of emotions on pain (Helmstetter et al., 1998). Stressful situations like physical exercise, exposure to extreme temperatures, fight, fear and pain may induce a decrease in pain sensitivity (Amit and Galina, 1986; Terman and Bonica, 2001), a phenomenon called stressinduced analgesia. The hypothalamus is involved in stress-induced analgesia, since a lesion of the arcuate nucleus (Millan et al., 1980) or paraventricular nucleus (Truesdell and Bodnar, 1987) attenuates stress-induced analgesia, and electrical stimulation of the hypothalamus results in spinal antinociception (e.g. Bach and Yaksh, 1995). Stress activates the hypothalamo pituitary-adrenal axis by releasing the corticotrophin releasing factor in the hypothalamus (Lariviere and Melzack, 2000) and this may result in modulation of pain due to endocrine mechanisms (Blackburn-Munro and Blackburn-Munro, 2003). 
Alternatively or in parallel, stress may induce spinal antinociception through axonal projections from the hypothalamus to the PAG-RVM circuitry (Sim and Joseph, 1991). Stress-induced analgesia may be based on opioid or non-opioid mechanisms depending on several factors such as severity of the stress (Mogil et al., 1996) and the body region to which stress-inducing stimulation is applied (Watkins and Mayer, 1982). Lesions of the dorsolateral funiculus attenuate both opioid and non-opioid forms of stress-induced analgesia indicating that descending medullo-spinal pathways have a significant role in mediating the spinal antinociceptive action induced by stress (Watkins and Mayer, 1982; Lewis et al., 1983).

\section{(b) Descending Noradrenergic Pain Inhibitory Pathways}

\section{Noradrenergic Pain Modulation: Noradrenergic}

Brainstem Nuclei

Noradrenaline is known to have a significant antinociceptive influence through action on spinal $\alpha_{2}$-adrenoceptors (Yaksh, 1985). The source of spinal noradrenaline is descending axons originating in the noradrenergic neuronal cell groups of the brainstem (Jones, 1991; Proudfit, 1988), particularly the locus coeruleus (or A6) but also noradrenergic cell groups A5 and A7 (Kwiat and Basbaum, 1992; Fig. 13.3). The locus coeruleus, A5 and A7 cell groups are connected with other paincontrol centers and all of them receive projections from

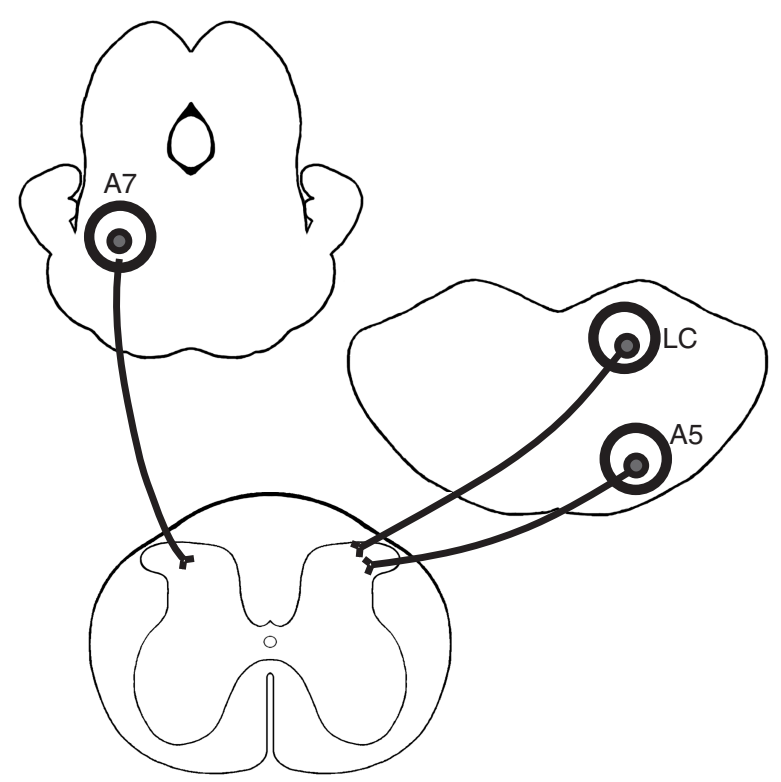

Fig. 13.3. Noradrenergic descending pain inhibitory pathways originating in the catecholaminergic nuclei of the brainstem. $\mathrm{LC}=$ locus coeruleus (A6). the PAG (Bajic and Proudfit, 1999). Additionally, the locus coeruleus receives projections from the central nucleus of the amygdala, preoptic area, paraventricular nucleus of the hypothalamus and lateral hypothalamus (Cedarbaum and Aghajanian, 1978). Of the nuclei projecting to noradrenergic cell groups of the brainstem, the parabrachial nucleus is noteworthy since it is an important relay for nociceptive signals from the superficial laminas of the spinal cord to the amygdala and hypothalamus, structures involved in control of emotional responses and stress, respectively (Bernard et al., 1996; Gauriau and Bernard, 2002). Due to their anatomical connections to multiple forebrain areas, the descending noradrenergic systems provide a putative subcortical relay for descending antinociceptive actions from some forebrain areas (Jasmin et al., 2004). Moreover, the descending analgesic influence triggered by PAG stimulation is partially mediated by recruitment of the descending noradrenergic system (Peng et al., 1996), through projections of the PAG and RVM to noradrenergic cell groups of the brainstem (Morton et al., 1984; Sim and Joseph, 1992; Bajic and Proudfit, 1999).

\section{Noradrenergic Pain Modulation: Spinal Cord Level}

Electrical stimulation of the noradrenergic locus coeruleus/subcoeruleus, A5 and A7 cell groups produces spinal antinociceptive effects (Burnett and Gebhart, 1991; Yeomans et al., 1992; West et al., 1993; Tsuruoka et al., 2004). Interestingly, activation of $\alpha_{2}$-adrenoceptors within the noradrenergic cell groups of the brainstem has not produced marked antinociceptive effects (Pertovaara et al., 1994; Mansikka and Pertovaara, 1995; however, Guo et al., 1996), but even hyperalgesia in some experimental conditions (Ossipov and Gebhart, 1986; Pertovaara et al., 1994). These findings suggest that spinal and supraspinal $\alpha_{2}$-adrenoceptors may have opposite effects on pain sensitivity. Ventrolateral pathways have a major role in mediating descending antinociceptive influences from the noradrenergic cell groups. This is shown by the finding that the antinociceptive effect induced by locus coeruleus stimulation is blocked by a lesion of the ventrolateral part of the spinal cord but not the dorsolateral funiculus (Mokha et al., 1986; Tsuruoka et al., 2004). At the spinal cord level, several pain inhibitory mechanisms may be activated by noradrenaline released from descending pathways. First, direct catecholaminergic innervation of the cell bodies of spinothalamic tracts neurons provides a structural basis for postsynaptic noradenergic inhibition of spinal pain-relay neurons (Westlund et al., 1990). Second, in the superficial laminas of the spinal dorsal horn noradrenaline activates a population of small, lowthreshold units that are likely to be inhibitory interneurons (Millar and Williams, 1989). Noradrenergic activation 
of inhibitory interneurons involves enhancement of GABAergic and glycinergic inhibitory synaptic transmission in the substantia gelatinosa (Baba et al., 2000). Third, noradrenaline inhibits transmission of nociceptive signals in the spinal cord due to action on presynaptic $\alpha_{2}$-adrenoceptors (particularly adrenoceptor subtype $\alpha_{2 \mathrm{~A}}$ ), as shown by the following findings: the primary location of $\alpha_{2 \mathrm{~A}}$-adrenoceptors in the spinal cord is the central terminals of nociceptive primary afferents (Stone et al., 1998), release of neurotransmitters from central terminals of nociceptive primary afferent nerve fibers is attenuated by noradrenaline (Kuraishi et al., 1985 ), noradrenaline induces $\alpha_{2}$-adrenoceptor antagonistreversible attenuation of responses of spinal dorsal horn neurons to dorsal root stimulation but not to direct administration of excitatory amino acids (Kawasaki et al., 2003) and exogenous $\alpha_{2}$-adrenoceptor agonists loose their antinociceptive potency in animals with a knockout of the $\alpha_{2 \mathrm{~A}}$-adrenoceptors (e.g. Stone et al., 1997). Another receptor subtype, $\alpha_{2 \mathrm{C}}$-adrenoceptor, is also found in the spinal dorsal horn, although its distribution is very different from that of $\alpha_{2 \mathrm{~A}}$-adrenoceptors. Namely, $\alpha_{2 \mathrm{C}}$-adrenoceptors are located on axon terminals of spinal interneurons that are likely to be excitatory ones and that innervate presumably nociceptive neurons with ascending projections to the medulla (Olave and Maxwell, 2003). These anatomical findings support the hypothesis that spinal $\alpha_{2 \mathrm{C}}$-adrenoceptors have painsuppressive effects by inhibiting presynaptically pronociceptive spinal interneurons. Axon terminals with spinal $\alpha_{2 C^{-}}$and $\alpha_{2 A^{-}}$-adrenoceptors receive only sparse, if any, direct contacts from descending noradrenergic pathways. Therefore, volume transmission is likely to play a major role in the spread of noradrenaline from descending axon terminals to the site of $\alpha_{2}$-adrenergic action within the spinal cord.

Noradrenergic Pain Modulation: Physiological Role The descending noradrenergic systems have a low tonic activity, since $\alpha_{2}$-adrenoceptor antagonists (Pertovaara, 1993) or knockouts of various subtypes of $\alpha_{2}$-adrenoceptors (Malmberg et al., 2001) have not consistently produced increases in pain-related responses to brief noxious stimuli in animals without sustained pain. A knockout of the dopamine, $\beta$-hydroxylase gene led to absence of noradrenaline and it had only minor and submodality selective effects on pain sensitivity (Jasmin et al., 2002) supporting the concept that noradrenergic systems have little influence on baseline pain sensitivity. During persistent pain, however, noradrenergic systems have a more important role. This is shown by the findings that a lesion of the noradrenergic locus coeruleus (Tsuruoka and Willis, 1996) or a knockout of $\alpha_{2 \mathrm{~A}}$-adrenoceptors (Mansikka et al., 2004) significantly increased pain-related reflex responses in animals with inflammatory pain, indicating an involvement of the noradrenergic feedback inhibition in the regulation of sustained pain.

\section{(c) Other Brain Areas Involved in Descending Inhibition of Pain}

In addition to the PAG-RVM-dorsal horn circuitry and the noradrenergic nuclei of the brainstem, a large number of other brain areas from the telencephalon to the caudal medulla have been shown to inhibit pain-related responses following electrical or chemical stimulation (Millan, 2002). For many of these structures the more exact role in pain regulation still needs to be studied. Moreover, it should be noted that the PAG-RVM-spinal dorsal horn circuitry and the descending noradrenergic systems also provide final common pathways for most of the other pain inhibitory areas some of which have already been dealt with in previous chapters (see above).

In the brainstem, antinociceptive actions were triggered from the ventral, lateral and gigantocellular reticular nuclei, the nucleus tractus solitarius (Aicher and Randich, 1990), caudal ventrolateral medulla (Tavares and Lima, 2002), cuneiform nucleus (Zemlan and Behbehani, 1988), deep mesencephalic nucleus (Wang et al., 1992), deep layers of the superior colliculus (Coimbra and Brandao, 1997), anterior pretectal nucleus (Rees and Roberts, 1993) and posterior hypothalamic area (Manning and Franklin, 1998). All of these areas receive afferents from (Yezierski, 1988; Lima et al, 1991; Iwata et al., 1998) and project directly to (Newman, 1985; Tavares and Lima, 1994; Tracey, 2004) the spinal cord. Putative pain-inhibiting areas projecting to the spinal cord but not receiving spinal afferents include the pedunculopontine tegmental nucleus (Iwamoto, 1991), somatosensory (Yezierski et al., 1983; Kuroda et al, 2001) and motor cortex (Brown and Barbaro, 2003). Some of the putative antinociceptive areas, like the ventral tegmental nucleus (Sotres-Bayon et al., 2001), receive spinal afferents but do not project to the spinal dorsal horn. Among the brain areas that appear to have a role in descending pain regulation but which do not have direct connections to or from the spinal cord are the basal ganglia (Chudler and Dong, 1995), particularly the striatum (Hagelberg et al., 2004) and substantia nigra (Baumeister, 1991) and the nucleus accumbens (Gear and Levine, 1995). The cerebellum, an important part of motor control circuitry, appears to have a role also in descending pain regulation, since stimulation of the fastigial nucleus suppressed spinal responses evoked by nociceptive visceral stimulation (Saab and Willis, 2002). Interestingly, covariance analysis of human brain imaging data indicate that 
attention-related modulation of pain may be based on "top down" modulation of nociception by descending brainstem-spinal pathways from the dorsolateral prefrontal cortex (Lorenz et al., 2003), and activation of the PAG-RVM circuitry by descending influence from the rostral anterior cingular cortex may have a major contribution to placebo- as well as opioid-induced analgesia (Petrovic et al., 2002).

\subsection{Summary}

The magnitude of the ascending nociceptive signal and the consequent pain sensation can be greatly influenced by descending pathways originating in the brainstem and terminating in the spinal dorsal horn. The bestknown descending circuitries involved in pain inhibition are the PAG-RVM-spinal cord pathway and the descending noradrenergic pathways. Descending painregulatory pathways are subject to "bottom up" (feedback inhibition) as well as "top down" control (e.g. cognitive and emotional regulation). The descending inhibitory effect is mediated by a number of neurotransmitters such as monoamines, peptides and amino acids, and by several different types of neurophysiological mechanisms acting on central terminals of primary afferent nociceptive nerve fibers, spinal interneurons and spinal projection neurons. In conditions that cause persistent pain, such as inflammation or injury, the function of descending pathways may change considerably. These changes may enhance the efficacy of descending inhibition. Alternatively, depending on a number of factors, injury and inflammation may result in a decrease of descending inhibition or an increase of descending facilitation of pain. Moreover, disorders of neurotransmitter systems per se potentially lead to hypofunction of descending pain-inhibition and consequently, to chronic pain. The function of descending pain-inhibitory systems may be enhanced by some centrally acting drugs (e.g. drugs acting on monoaminergic system or opioid receptors), direct stimulation of brain areas involved in descending inhibitory controls, indirect activation of descending pathways with peripheral stimulation ("bottom up" activation) or using behavioral manipulations ("top down" activation). Further understanding of the pain-inhibitory systems may provide new pharmacological, physical and behavioral methods for treating chronic pain. Finally, it should be noted that many of the neural structures involved in descending pain inhibition also have other functions such as control of vigilance, motor behavior, circulation and respiration.

\section{Abbreviations}

$\mathrm{DNIC}=$ diffuse noxious inhibitory controls; $\mathrm{PAG}=$ periaqueductal gray; RVM = rostral ventromedial medulla

\section{Acknowledgments}

The authors have been supported by the Academy of Finland (grant 78582), the Sigrid Jusélius Foundation, Finland, Grünenthal Foundation, Portugal and Project no POCTI/NSE/46399/2002 from FCT and FEDER, Portugal. The authors wish to thank Dr. Denis Artchakov for illustrations.

\section{References}

Aicher SA, Randich A (1990). Antinociception and cardiovascular responses produced by electrical stimulation in the nucleus tractus solitarius, nucleus reticularis ventralis, and the caudal medulla. Pain 42: 103-119.

Aimone LD, Gebhart GF (1988). Serotonin and/or an excitatory amino acid in the medial medulla mediates stimulationproduced antinociception from the lateral hypothalamus in the rat. Brain Res 450: 170-180.

Aimone LD, Jones SL, Gebhart GF (1987). Stimulationproduced descending inhibition from the periaqueductal gray and nucleus raphe magnus in the rat: mediation by spinal monoamines but not opioids. Pain 123-136.

Almeida A, Tjølsen A, Lima D, Coimbra A, Hole K (1996). The medullary dorsal reticular nucleus facilitates acute nociception in the rat. Brain Res Bull 39: 7-15.

Almeida A, Storkson R, Lima D, Hole K, Tjølsen A (1999). The medullary dorsal reticular nucleus facilitates pain behaviour induced by formalin in the rat. Eur J Neurosci 11: $110-122$.

Amit Z, Galina H (1986). Stress-induced analgesia: adaptive pain suppression. Physiol Rev 66: 1091-1120.

Baba H, Shimoji K, Yoshimura M (2000). Norepinephrine facilitates inhibitory transmission in substantia gelatinosa of adult rat spinal cord (part 1): effects on axon terminals of GABAergic and glycinergic neurons. Anesthesiology 92: 473-484.

Bach FW, Yaksh TL (1995). Release into ventriculo-cisternal perfusate of beta-endorphin- and Met-enkephalinimmunoreactivity: effects of electrical stimulation in the arcuate nucleus and periaqueductal gray of the rat. Brain Res 690: 167-176.

Bajic D, Proudfit HK (1999). Projections of neurons in the periaqueductal gray to pontine and medullary catecholamine cell groups involved in the modulation of nociception. J Comp Neurol 405: 359-379.

Bandler R, McCulloch T, Dreher B (1985). Afferents to midbrain periaqueductal grey region involved in the 'defence reaction' in the cat as revealed by horseradish peroxidase. I. The telencephalon. Brain Res. 330: 109-119.

Basbaum AI, Clanton CH, Fields HL (1976). Opiate and stimulus-produced analgesia: functional anatomy of medullospinal pathway. Proc Natl Acad Sci USA 73: $4685-4688$.

Baumeister AA (1991). The effects of bilateral intranigral microinjection of selective opioid agonists on behavioral responses to noxious thermal stimulation. Brain Res 557: 136-145. 
Behbehani MM, Fields HL (1979). Evidence that an excitatory connection between the periaqueductal grey and nucleus raphe magnus mediates stimulation-produced analgesia. Brain Res 170: 85-93.

Bernard JF, Bester H, Besson JM (1996). Involvement of the spino-parabrachio-amygdaloid and -hypothalamic pathways in the autonomic and affective emotional aspects of pain. Prog Brain Res 107: 243-255.

Bing Z, Villanueva L, Le Bars D (1990). Acupuncture and diffuse noxious inhibitory controls: naloxone-reversible depression of activities of trigeminal convergent neurons. 37: 809-818.

Blackburn-Munro G, Blackburn-Munro R (2003). Pain in the brain: are hormones to blame? Trends Endocrinol Metab 14: 20-27.

Bouhassira D, Villanueva L, Bing Z, Le Bars D (1992). Involvement of the subnucleus reticularis dorsalis in diffuse noxious inhibitory controls in the rat. Brain Res 595: 353-357.

Bouhassira D, Gall O, Chitour D, Le Bars D (1995). Dorsal horn convergent neurones: negative feedback triggered by spatial summation of nociceptive afferents. Pain 62 : 195-200.

Brandt SA, Livingston A (1990). Receptor changes in the spinal cord of sheep associated with exposure to chronic pain. Pain 42: 323-329.

Brown JA, Barbaro NM (2003). Motor cortex stimulation for central and neuropathic pain: current status. Pain 104: 431-435.

Burnett A, Gebhart GF (1991). Characterization of descending modulation of nociception from the A5 cell group. Brain Res 546: 271-281.

Calvino B, Villanueva L, Le Bars D (1987). Dorsal horn (convergent) neurones in the intact anesthetized arthritic rat: II. Heterotopic inhibitory influences. Pain 31: 359-379.

Carstens E, Klumpp D, Zimmermann M (1980). Differential inhibitory effects of medial and lateral midbrain stimulation on spinal neuronal discharges to noxious skin heating in the cat. J Neurophysiol 43: 332-342.

Cedarbaum JM, Aghajanian GK (1978). Afferent projections to the rat locus coeruleus as determined by a retrograde tracing technique. J Comp Neurol 178: 1-16.

Chudler EH, Dong WK (1995). The role of the basal ganglia in nociception and pain. Pain 60: 3-38.

Coimbra A, Brandao ML (1997). Effects of 5-HT 2 receptors blockade on fear-induced analgesia elicited by electrical stimulation of the deep layers of the superior colliculus and dorsal periaqueductal gray. Behav Brain Res 87: 97-103.

Cui M, Feng Y, McAdoo DJ, Willis WD (1999). Periaqueductal gray stimulation-induced inhibition of nociceptive dorsal horn neurons in rats is associated with the release of norepinephrine, serotonin, and amino acids. J Pharmacol Exp Ther 289: 868-876.

Danziger N, Weil-Fugazza J, Le Bars D, Bouhassira D (1999). Alteration of descending modulation of nociception during the course of monoarthritis in the rat. J Neurosci 19: 2394-2400.

DeLong MR (2000). The basal ganglia. In: Kandel ER, Schwartz JH, Jessell TM (Eds.) Principles of Neural Science, 4th edn. McGraw Hill, New York, pp. 853-867.
Dickhaus H, Pauser G, Zimmermann M (1985). Tonic descending inhibition affects intensity coding of nociceptive responses of spinal dorsal horn neurones in the cat. Pain 23: 145-158.

Dong YF, Tang JS, Yuan B, Jia H (1999). Morphine applied to the thalamic nucleus submedius produces a naloxone reversible antinociceptive effect in the rat. Neurosci Lett 271: 17-20.

Dubner R (1985). Specialization in nociceptive pathways: sensory discrimination, sensory modulation, and neural connectivity. Adv Pain Res Ther 9: 111-137.

Dugast C, Almeida A, Lima D (2003). The medullary dorsal reticular nucleus enhances the responsiveness of spinal nociceptive neurons to peripheral stimulation in the rat. Eur J Neurosci 18: 580-588.

Eltahawy HA, Saint-Cyr J, Poon YY, Moro E, Lang AE, Lozano AM (2004). Pallidal deep brain stimulation in cervical dystonia. Can J Neurol Sci 31: 328-332.

Fields HL, Basbaum AI (1999). Central nervous system mechanisms of pain modulation. In: Wall PD, Melzack R (Eds.) Textbook of Pain, 4th edn. Churchill Livingstone, Hong Kong, pp. 309-329.

Fields HL, Heinricher MM, Mason P (1991). Neurotransmitters in nociceptive modulatory circuits. Annu Rev Neurosci 14: 219-245.

Fitzgerald M, Koltzenburg M (1986). The functional development of descending inhibitory pathways in the dorsolateral funiculus of the newborn rat spinal cord. Brain Res 389: 261-270.

Franzini A, Ferroli P, Leone M, Broggi G (2003). Stimulation of the posterior hypothalamus for treatment of chronic intractable cluster headaches: first reported series. Neurosurgery 52: 1095-1099.

Gauriau C, Bernard JF (2002). Pain pathways and parabrachial circuits in the rat. Exp Physiol 87: 251-258.

Gear RW, Levine JD (1995). Antinociception produced by an ascending spino-supraspinal pathway. J Neurosci 15: 3154-3161.

Gebhart GF (2004). Descending modulation of pain. Neurosci Biobehav Rev 27: 729-737.

Gebhart GF, Sandkühler J, Thalhammer JG, Zimmermann M (1983). Quantitative comparison of inhibition in spinal cord of nociceptive information by stimulation in periaqueductal gray or nucleus raphe magnus of the cat. J Neurophysiol 50: $1433-1445$.

Giesler GJ, Gerhart KD, Yezierski RP, Wilcox TK, Willis WD (1981). Postsynaptic inhibition of primate spinothalamic neurons by stimulation in nucleus raphe magnus. Brain Res 204: 184-188.

Gray BG, Dostrovsky JO (1983). Descending inhibitory influences from periaqueductal gray, nucleus raphe magnus, and adjacent reticular formation. I. Effects on lumbar spinal cord nociceptive and non-nociceptive neurons. J Neurophysiol 49: 932-947.

Guo TZ, Jiang JY, Buttermann AE, Maze M (1996). Dexmedetomidine injection into the locus coeruleus produces antinociception. Anesthesiology 84: 873-881.

Hagelberg N, Jääskeläinen SK, Martikainen IK, Mansikka H, Forssell H, Scheinin H, Hietala J, Pertovaara A (2004). Striatal dopamine D2 receptors in modulation of pain in humans: a review. Eur J Pharmacol 500: 187-192. 
Hall JG, Duggan AW, Morton CR, Johnson SM (1982). The location of brainstem neurones tonically inhibiting dorsal horn neurones of the cat. Brain Res 244: 215-222.

Hardy SG (1986). Projections to the midbrain from the medial versus lateral prefrontal cortices of the rat. Neurosci Lett 63: 159-164.

Heinricher MM, Morgan MM, Fields HL (1992). Direct and indirect actions of morphine on medullary neurons that modulate nociception. Neuroscience 48: 533-543.

Helmstetter FJ, Tershner SA, Poore LH, Bellgowan PS (1998). Antinociception following opioid stimulation of the basolateral amygdala is expressed through the periaqueductal gray and rostral ventromedial medulla. Brain Res 779 : 104-118.

Hodge CJ Jr, Apkarian AV, Owen MP, Hanson BS (1983). Changes in the effects of stimulation of locus coeruleus and nucleus raphe magnus following dorsal rhizotomy. Brain Res 288: 325-329.

Hosobuchi Y (1986). Subcortical electrical stimulation for control of intractable pain in humans. Report of 122 cases (1970-1984). J Neurosurg 64: 543-553.

Iwamoto ET (1991). Characterization of the antinociception induced by nicotine in the pedunculopontine tegmental nucleus and the nucleus raphe magnus. J Pharmacol Exp Ther 257: 120-133.

Iwata K, Tsuboi Y, Tashiro A, Sakamoto M, Hagiwara S, Kohno M, Sumino R (1998). Mesencephalic projections from superficial and deep laminae of the medullary dorsal horn. J Oral Sci 40: 159-163.

Iwata K, Fukuoka T, Kondo E, Tsuboi Y, Tashiro A, Noguchi K, Masuda Y, Morimoto T, Kanda K (2002). Plastic changes in nociceptive transmission of the rat spinal cord with advancing age. J Neurophysiol 87: 1086-1093.

Jasmin L, Tien D, Weinshenker D, Palmiter RD, Green PG, Janni G, Ohara PT (2002). The NK1 receptor mediates both the hyperalgesia and the resistance to morphine in mice lacking noradrenaline. Proc Natl Acad Sci USA 99: 1029-1034.

Jasmin L, Granato A, Ohara PT (2004). Rostral agranular insular cortex and pain areas of the central nervous system: a tract-tracing study in the rat. J Comp Neurol 468: 425-440.

Jensen TS, Yaksh TL (1984). Spinal monoamine and opiate systems partly mediate the antinociceptive effects produced by glutamate at brainstem sites. Brain Res 321: 287-297.

Jones SL (1991). Descending noradrenergic influences on pain. Prog Brain Res 88: 381-394.

Kalmari J, Pertovaara A (2004). Colorectal distensioninduced suppression of a nociceptive somatic reflex response in the rat: modulation by tissue injury or inflammation. Brain Res 1018: 106-110.

Kamei J, Aoki T, Kasuya Y (1992). Periaqueductal gray matter stimulation-produced analgesia in diabetic rats. Neurosci Lett 142: 13-16.

Katayama Y, Yamamoto T, Kobayashi K, Kasai M, Oshima H, Fukaya C (2001). Motor cortex stimulation for post-stroke pain: comparison of spinal cord and thalamic stimulation. Stereotact Funct Neurosurg 77: 183-186.

Kauppila T, Kontinen VK, Pertovaara A (1998). Influence of spinalization on spinal withdrawal reflex responses varies depending on the submodality of the test stimulus and the experimental pathophysiological condition in the rat. Brain Res 797: 234-242.

Kawasaki Y, Kumamoto E, Furue H, Yoshimura M (2003). $\alpha_{2}$-Adrenoceptor-mediated presynaptic inhibition of primary afferent glutamatergic transmission in rat substantia gelatinosa neurons. Anesthesiology 98: 682-689.

Kosek E, Hansson P (1997). Modulatory influence on somatosensory perception from vibration and heterotopic noxious conditioning stimulation (HNCS) in fibromyalgia patients and healthy subjects. Pain 70: 41-51.

Krauss JK, Pohle T, Weigel R, Burgunder JM (2002). Deep brain stimulation of the centre median-parafascicular complex in patients with movement disorders. J Neurol Neurosurg Psychiatry 72: 546-548.

Kuraishi Y, Hirota N, Sato Y, Satoh M, Takagi H (1985). Noradrenergic inhibition of the release of substance $\mathrm{P}$ from primary afferents in the rabbit spinal dorsal horn. Brain Res 359: 177-182.

Kuroda R, Kawao N, Yoshimura H, Umeda W, Takemura M, Shigenaga Y, Kawabata A (2001). Secondary somatosensory cortex stimulation facilitates the antinociceptive effect of the NO synthase inhibitor through suppression of spinal nociceptive neurons in the rat. Brain Res 903: 110-116.

Kwiat GC, Basbaum AI (1992). The origin of brainstem noradrenergic and serotoninergic projections to the spinal cord dorsal horn in the rat. Somatosens Mot Res 9: 157-173.

Laird JM, Cervero F (1990). Tonic descending influences on receptive-field properties of nociceptive dorsal horn neurons in sacral spinal cord of rat. J Neurophysiol 63: 1022-1032.

Lakos S, Basbaum AI (1988). An ultrastructural study of the projections from the midbrain periaqueductal gray to spinally projecting, serotonin-immunoreactive neurons of the medullary nucleus raphe magnus in the rat. Brain Res 443: 383-388.

Lariviere WR, Melzack R (2000). The role of corticotrophinreleasing factor in pain and analgesia. Pain 84: 1-12.

Le Bars D, Dickenson AH, Besson JM (1979a). Diffuse noxious inhibitory controls (DNIC). I. Effects on dorsal horn convergent neurones in the rat. Pain 6: 283-304.

Le Bars D, Dickenson AH, Besson JM (1979b). Diffuse noxious inhibitory controls (DNIC). II. Lack of effect on non-convergent neurones, supraspinal involvement and theoretical implications. Pain 6: 305-327.

Leong SK, Shieh JY, Wong WC (1984). Localizing spinalcord-projecting neurons in neonatal and immature albino rats. J Comp Neurol 228: 18-23.

Levine R, Morgan MM, Cannon JT, Liebeskind JC (1991). Stimulation of the periaqueductal gray matter of the rat produces a preferential ipsilateral antinociception. Brain Res 567: 140-144.

Lewis JW, Terman GW, Watkins LR, Mayer DJ, Liebeskind JC (1983). Opioid and non-opioid mechanisms of footshockinduced analgesia: role of the spinal dorsolateral funiculus. Brain Res 267: 139-144.

Light AR, Casale EJ, Menetrey DM (1986). The effects of focal stimulation in nucleus raphe magnus and periaqueductal gray on intracellularly recorded neurons in spinal laminae I and II. J Neurophysiol 56: 555-571. 
Lima D, Almeida A (2002). The medullary dorsal reticular nucleus as a pronociceptive centre of the pain control system. Prog Neurobiol 66: 81-108.

Lima D, Mendes-Ribeiro JA, Coimbra A (1991). The spinolatero-reticular system of the rat: projections from the superficial dorsal horn and structural characterization of marginal neurons involved. Neuroscience 45: 137-152.

Lorenz J, Minoshima S, Casey KL (2003). Keeping pain out of mind: the role of the dorsolateral prefrontal cortex in pain modulation. Brain 126: 1079-1091.

Ma W, Eisenach JC (2003). Chronic constriction injury of sciatic nerve induces the up-regulation of descending inhibitory noradrenergic innervation to the lumbar dorsal horn of mice. Brain Res 970: 110-118.

Malmberg AB, Hedley LR, Jasper JR, Hunter JC, Basbaum AI (2001). Contribution of $\alpha_{2}$ receptor subtypes to nerve injuryinduced pain and its regulation by dexmedetomidine. $\mathrm{Br} \mathrm{J}$ Pharmacol 132: 1827-1836.

Manning BH, Franklin KB (1998). Morphine analgesia in the formalin test: reversal by microinjection of quaternary naloxone into the posterior hypothalamic area or periaqueductal gray. Behav Brain Res 92: 97-102.

Mansikka H, Pertovaara A (1995). The role of $\alpha_{2}$-adrenoceptors of the medullary lateral reticular nucleus in spinal antinociception in rats. Brain Res Bull 37: 633-638.

Mansikka H, Idänpään-Heikkilä JJ, Pertovaara A (1996). Different roles of $\alpha_{2}$-adrenoceptors of the medulla versus the spinal cord in modulation of mustard oil-induced central hyperalgesia in rats. Eur J Pharmacol 297: 19-26.

Mansikka H, Lähdesmäki J, Scheinin M, Pertovaara A (2004). $\alpha_{2 \mathrm{~A}}$-Adrenoceptors contribute to feedback inhibition of capsaicin-induced hyperalgesia. Anesthesiology 101: 185-190.

Mansour A, Fox CA, Burke S, Meng F, Thompson RC, Akil H, Watson SJ (1994). Mu, delta and kappa opioid receptor mRNA expression in the rat CNS: an in situ hybridization study. J Comp Neurol 350: 412-438.

Martin RF, Haber LH, Willis WD (1979). Primary afferent depolarization of identified cutaneous fibers following stimulation in medial brain stem. J Neurophysiol 42: 779-790.

Mason P (1997). Physiologic identification of pontomedullary serotoninergic neurons in the rat. J Neurophysiol 77: 1087-1098.

Mayer DJ, Wolfle TL, Akil H, Carder B, Liebeskind JC (1971). Analgesia from electrical stimulation in the brainstem of the rat. Science 174: 1351-1354.

McNally GP (1999). Pain facilitatory circuits in the mammalian central nervous system: their behavioral significance and role in morphine analgesic tolerance. Neurosci Biobehav Rev 23: 1059-1078.

Meyerson BA (2001). Neurosurgical approaches to pain treatment. Acta Anaesthesiol Scand 45: 1108-1113.

Miki K, Zhou QQ, Guo W, Guan Y, Terayama R, Dubner R, Ren K (2002). Changes in gene expression and neuronal phenotype in brain stem pain modulatory circuitry after inflammation. J Neurophysiol 87: 750-760.

Millan MJ (2002). Descending control of pain. Prog Neurobiol 66: $355-474$.
Millan MJ, Gramsch C, Przewlocki R, Hollt V, Herz A (1980). Lesions of the hypothalamic arcuate nucleus produce a temporary hyperalgesia and attenuate stress-evoked analgesia. Life Sci 27: 1513-1523.

Millar J, Williams GV (1989). Effect of iontophoresis of noradrenaline and stimulation of the periaqueductal gray on single-unit activity in the rat superficial dorsal horn. J Comp Neurol 287: 119-133.

Mogil JS, Sternberg WF, Balian H, Liebeskind JC, Sadowski B (1996). Opioid and nonopioid swim stress-induced analgesia: a parametric analysis in mice. Physiol Behav 59: 123-132.

Mokha SS, McMillan JA, Iggo A (1986). Pathways mediating descending control of spinal nociceptive transmission from the nuclei locus coeruleus (LC) and raphe magnus (NRM) in the cat. Exp Brain Res 61: 597-606.

Morgan MM, Sohn JH, Liebeskind JC (1989). Stimulation of the periaqueductal gray matter inhibits nociception at the supraspinal as well as spinal level. Brain Res 502: 61-66.

Morgan MM, Gold MS, Liebeskind JC, Stein C (1991). Periaqueductal gray stimulation produces a spinally mediated, opioid antinociception for the inflamed hindpaw of the rat. Brain Res 545: 17-23.

Morton CR, Duggan AW, Zhao ZQ (1984). The effects of lesion of medullary midline and lateral reticular areas on inhibition in the dorsal horn produced by periaqueductal grey stimulation in the cat. Brain Res 301: 121-130.

Morton CR, Siegel J, Xiao HM, Zimmermann M (1997). Modulation of cutaneous nociceptor activity by electrical stimulation in the brain stem does not inhibit the nociceptive excitation of dorsal horn neurons. Pain 71: 65-70.

Nandi D, Aziz T, Carter H, Stein J (2003). Thalamic field potentials in chronic central pain treated by periventricular gray stimulation - a series of eight cases. Pain 101: 97-107.

Newman DB (1985). Distinguishing rat brainstem reticulospinal nuclei by their neuronal morphology. I. Medullary nuclei. J Hirnforsch 26: 187-226.

North RA, Yoshimura M (1984). The actions of noradrenaline on neurones of the rat substantia gelatinosa in vitro. J Physiol (Lond) 349: 43-55.

Olave MJ, Maxwell DJ (2003). Neurokinin-1 projection cells in the rat dorsal horn receive synaptic contacts from axons that possess $\alpha_{2 C}$-adrenergic receptors. J Neurosci 23: 6837-6846.

Ossipov MH, Gebhart GF (1986). Opioid, cholinergic and alpha-adrenergic influences on the modulation of nociception from the lateral reticular nucleus of the rat. Brain Res 384: 282-293.

Paredes J, Winters RW, Schneiderman N, McCabe PM (2000). Afferents to the central nucleus of the amygdala and functional subdivisions of the periaqueductal gray: neuroanatomical substrates for affective behavior. Brain Res 887: 157-173.

Peng YB, Lin Q, Willis WD (1996). Involvement of alpha-2 adrenoceptors in the periaqueductal gray-induced inhibition of dorsal horn cell activity in rats. J Pharmacol Exp Ther 278: 125-135.

Pertovaara A (1993). Antinociception induced by alpha-2adrenoceptor agonists, with special emphasis on medetomidine studies. Prog Neurobiol 40: 691-709. 
Pertovaara A (1999). The influence of stimulus temperature rise rate, adapting temperature, and stimulus duration on suprathreshold responses evoked by noxious heat in the glabrous skin of the limb. Comparison of neuronal discharge in the rat spinal dorsal horn with human sensations. Exp Brain Res 126: 482-494.

Pertovaara A (2000). Plasticity in descending pain modulatory systems. Prog Brain Res 129: 231-242.

Pertovaara A, Kemppainen P, Johansson G, Karonen SL (1982). Ischemic pain nonsegmentally produces a predominant reduction of pain and thermal sensitivity in man: a selective role for endogenous opioids. Brain Res 251: 83-92.

Pertovaara A, Hämäläinen MM, Kauppila T, Mecke E, Carlson S (1994). Dissociation of the $\alpha_{2}$-adrenergic antinociception from sedation following microinjection of medetomidine into the locus coeruleus in rats. Pain 57: 207-215.

Pertovaara A, Kontinen VK, Kalso E (1997). Chronic spinal nerve ligation induces changes in response characteristics of nociceptive spinal dorsal horn neurons and in their descending regulation originating in the periaqueductal gray in the rat. Exp Neurol 147: 428-436.

Pertovaara A, Wei H, Kalmari J, Ruotsalainen M (2001). Pain behavior and response properties of spinal dorsal horn neurons following experimental diabetic neuropathy in the rat: modulation by nitecapone, a COMT inhibitor with antioxidant properties. Exp Neurol 167: 425-434.

Petrovic P, Kalso E, Petersson KM, Ingvar M (2002). Placebo and opioid analgesia - imaging a shared network. Science 295: 1737-1740.

Porreca F, Ossipov MH, Gebhart GF (2002). Chronic pain and medullary descending facilitation. Trends Neurosci 25: 319-325.

Proudfit HK (1988). Pharmacologic evidence for the modulation of nociception by noradrenergic neurons. Prog Brain Res 77: 357-370.

Rainov NG, Heidecke V (2003). Motor cortex stimula-tion for neuropathic facial pain. Neurol Res 25: 157-161.

Rees H, Roberts MH (1993). The anterior pretectal nucleus: a proposed role in sensory processing. Pain 53: 121-135.

Ren K, Dubner R (1996). Enhanced descending modulation of nociception in rats with persistent hindpaw inflammation. J Neurophysiol 76: 3025-3037.

Ren K, Dubner R (2002). Descending modulation in persistent pain: an update. Pain 100: 1-6.

Reynolds DV (1969). Surgery in the rat during electrical analgesia induced by focal brain stimulation. Science 164 : 444-445.

Rivot JP, Weil-Fugazza J, Godefroy F, Bineau-Thurotte M, Ory-Lavollée, Besson JM (1984). Involvement of serotonin in both morphine and stimulation-produced analgesia: electrochemical and biochemical approaches. Adv Pain Res Ther 6: 135-150.

Ruda MA, Bennett GJ, Dubner R (1986). Neurochemistry and neural circuitry in the dorsal horn. Prog Brain Res 66: 219-268.

Rudomin P, Schmidt RF (1999). Presynaptic inhibition in the vertebrate spinal cord revisited. Exp Brain Res 129: 1-37.
Saab CY, Willis WD (2002). Cerebellar stimulation modulates the intensity of a visceral nociceptive reflex in the rat. Exp Brain Res 146: 117-121.

Saitoh Y, Hirano S-I, Kato A, Kishima H, Hirata M, Yamamoto K, Yoshimine T (2001). Motor cortex stimulation for deafferentation pain. Neurosurg Focus 11: 1-5.

Sakata S, Shima F, Kato M, Fukui M (1989). Dissociated mesencephalic responses to medial and ventral thalamic nuclei stimulation in rats. Relationship to analgesic mechanisms. J Neurosurg 70: 446-453.

Sandkühler J (1996) The organization and function of endogenous antinociceptive systems. Prog Neurobiol 50: 49-81.

Sandkühler J, Liu X (1998). Induction of long-term potentiation at spinal synapses by noxious stimulation or nerve injury. Eur J Neurosci 10: 2476-2480.

Schaible HG, Neugebauer V, Cervero F, Schmidt RF (1991). Changes in tonic descending inhibition of spinal neurons with articular input during the development of acute arthritis in the cat. J Neurophysiol 66: 1021-1032.

Sim LJ, Joseph SA (1991). Arcuate nucleus projections to brainstem regions which modulate nociception. J Chem Neuroanat 4: 97-109.

Sim LJ, Joseph SA (1992). Efferent projections of the nucleus raphe magnus. Brain Res Bull 28: 679-682.

Sol JC, Casaux J, Roux FE, Lotterie JA, Bousquet P, Verdie JC, Mascott C, Lazorthes Y (2001). Chronic motor cortex stimulation for phantom limb pain: correlations between pain relief and functional imaging studies. Stereotact Funct Neurosurg 77: 172-176.

Sotres-Bayon F, Torres-Lopez E, Lopez-Avila A, del Angel R, Pellicer F (2001). Lesion and electrical stimulation of the ventral tegmental area modify persistent nociceptive behavior in the rat. Brain Res 898: 342-349.

Stanfa LC, Dickenson AH (1994). Enhanced $\alpha_{2}$-adrenergic controls and spinal morphine potency in inflammation. NeuroReport 5: 469-472.

Staud R, Robinson ME, Vierck CJ Jr, Price DD (2003). Diffuse noxious inhibitory controls (DNIC) attenuate temporal summation of second pain in normal males but not in normal females or fibromyalgia patients. Pain 101: 167-174.

Stone L, MacMillan LB, Kitto KF, Limbird LE, Wilcox GL (1997). The alpha-2A-adrenergic receptor subtype mediates spinal analgesia evoked by alpha-2-agonists and is necessary for spinal adrenergic-opioid synergy. J Neurosci 17: 7157-7165.

Stone LS, Broberger C, Vulchanova L, Wilcox GL, Hökfelt T, Riedl MS, Elde R (1998). Differential distribution of alpha2A and alpha2C adrenergic receptor immunoreactivity in the rat spinal cord. J Neurosci 18: 5928-5937.

Suzuki R, Rygh LJ, Dickenson AH (2004). Bad news from the brain: 5-HT pathways that control spinal pain processing. Trends Pharmacol Sci 25: 613-617.

Tasker RR (1982). Identification of pain processing systems by electrical stimulation of the brain. Hum Neurobiol 1: 261-272.

Tavares I, Lima D (1994). Descending projections from the caudal medulla oblongata to the superficial or deep dorsal horn of the rat spinal cord. Exp Brain Res 99: 455-463. 
Tavares I, Lima D (2002). The caudal ventrolateral medulla as an important inhibitory modulator of pain transmission in the spinal cord. J Pain 3: 337-346.

Terman GW, Bonica JJ (2001). Spinal mechanisms and their modulation. In: (Loeser JD, Butler SH, Chapman CR, Turk DC, (Eds.) Bonica's Management of Pain 3rd edn. Lippincott Williams \& Wilkins, New York, pp. 73-152.

Tracey D (2004). Ascending and descending pathways in the spinal cord. In: Paxinos, (Ed.), The Rat Nervous System 3rd edn. Elsevier pp. 149-163.

Truesdell LS, Bodnar RJ (1987). Reduction in cold-water swim analgesia following hypothalamic paraventricular nucleus lesions. Physiol Behav 39: 727-731.

Tsuruoka M, Willis WD (1996). Bilateral lesions in the area of the nucleus locus coeruleus affect the development of hyperalgesia during carrageenan-induced inflammation. Brain Res 726: 233-236.

Tsuruoka M, Maeda M, Nagasawa I, Inoue T (2004). Spinal pathways mediating coerulospinal antinociception in the rat. Neurosci Lett 362: 236-239.

Urban MO, Gebhart GF (1999). Supraspinal contributions to hyperalgesia. Proc Natl Acad Sci USA 96: 7687-7692.

Vanegas H, Schaible HG (2004). Descending control of persistent pain: inhibitory or facilitatory? Brain Res Rev 46: 295-309.

Vilela Filho O (1994). Thalamic ventrobasal stimulation for pain relief. Probable mechanisms, pathways and neurotransmitters. Arch Neuropsychiatry 52: 578-584.

Wang XM, Yuan B, Hou ZL (1992). Role of the deep mesencephalic nucleus in the antinociception induced by stimulation of the anterior pretectal nucleus in rats. Brain Res 577: 321-325.

Watkins LR, Mayer DJ (1982). Organization of endogenous opiate and nonopiate pain control systems. Science 216: 1185-1192.

Weil-Fugazza J, Godefroy F, Manceau V, Besson JM (1986). Increased norepinephrine and uric acid levels in the spinal cord of arthritic rats. Brain Res 374: 190-194.

West WL, Yeomans DC, Proudfit HK (1993). The function of noradrenergic neurons in mediating antinociception induced by electrical stimulation of the locus coeruleus in two different sources of Sprague-Dawley rats. Brain Res 626: $127-135$.
Westlund KN, Carlton SM, Zhang D, Willis WD (1990). Direct catecholaminergic innervation of primate spinothalamic tract neurons. J Comp Neurol 299: 178-186.

Willer JC, Roby A, Le Bars D (1984). Psychophysical and electrophysiological approaches to the pain-relieving effects of heterotopic nociceptive stimuli. Brain 107: 1095-1112.

Willis WD Jr, Coggeshall RE (1991). Sensory Mechanisms of the Spinal Cord. 2nd edn. Plenum Press, New York.

Witting N, Svensson P, Jensen TS (2003). Differential recruitment of endogenous pain inhibitory systems in neuropathic pain patients. Pain 103: 75-81.

Xu XJ, Puke MJC, Wiesenfeld-Hallin Z (1992). The depressive effect of intrathecal clonidine on the spinal flexor reflex is enhanced after sciatic nerve section in rats. Pain 51: $145-151$.

Xu M, Kontinen VK, Kalso E (1999). Endogenous noradrenergic tone controls symptoms of allodynia in the spinal nerve ligation model of neuropathic pain. Eur J Pharmacol 366: 41-45.

Yaksh TL (1985). Pharmacology of spinal adrenergic systems which modulate spinal nociceptive processing. Pharmacol Biochem Behav 22: 845-858.

Yaksh TL (1997). Pharmacology and mechanisms of opioid analgesic activity. Acta Anaesthesiol Scand 41: 94-111.

Yeomans DC, Clark FM, Paice JA, Proudfit HK (1992). Antinociception induced by electrical stimulation of spinally projecting noradrenergic neurons in the A7 catecholamine cell group of the rat. Pain 48: 449-461.

Yezierski RP (1988). Spinomesencephalic tract: projections from the lumbosacral spinal cord of the rat, cat, and monkey. J Comp Neurol 267: 131-146.

Yezierski RP, Gerhart KD, Schrock BJ, Willis WD (1983). A further examination of effects of cortical stimulation on primate spinothalamic tract cells. J Neurophysiol 49: 424-441.

Zemlan FP, Behbehani MM (1988). Nucleus cuneiformis and pain modulation: anatomy and behavioral pharmacology. Brain Res 453: 89-102.

Zhuo M, Gebhart GF (1990). Characterization of descending inhibition and facilitation from the nuclei reticularis gigantocellularis and gigantocellularis pars alpha in the rat. Pain 42: 337-350. 